\title{
Spatiotemporal dynamics of free-living stages of a bacterial parasite of zooplankton
}

\author{
Sara H. Thomas ${ }^{1,4}$, Christopher Bertram², Karla van Rensburg ${ }^{1},{\text { Carla E. } \text { Cáceres }^{2,3} \text {, }}_{\text {Meghan A. Duffy }}{ }^{1, *}$ \\ ${ }^{1}$ School of Biology, Georgia Institute of Technology, Atlanta, Georgia 30332, USA \\ ${ }^{2}$ Program in Ecology, Evolution and Conservation Biology, and ${ }^{3}$ School of Integrative Biology, University of Illinois, \\ Urbana-Champaign, Illinois 61820, USA \\ ${ }^{4}$ Present address: Marietta High School, 1171 Whitlock Ave SW, Marietta, Georgia 30064, USA
}

\begin{abstract}
Parasites are generally thought of as being intimately tied to their hosts, yet many parasites produce free-living stages. This raises the question: what are parasites doing when they are not being parasitic? We studied the spatiotemporal dynamics of free-living infectious stages and asked whether these dynamics were correlated with infections in 2 focal host species. We used a common and virulent bacterial parasite, Spirobacillus cienkowskii, which infects Daphnia spp. Densities of free-living infective stages were high in a stratified, eutrophic lake (up to $\sim 10^{5}$ to $10^{6}$ cells $\mathrm{l}^{-1}$ ), but also spatiotemporally variable. There was a positive correlation between the density of these freeliving stages and the prevalence of infected Daphnia on the subsequent sampling date. This suggests that free-living stages increase in environmental reservoirs prior to the start of epidemics in Daphnia. We also studied the ability of free-living stages to persist outside their hosts for long periods of time. In laboratory microcosms, we found that $S$. cienkowskii persisted under simulated environmental conditions for more than 2 mo, before declining to below our method's detection limit after approximately 3 mo. Overall, our study of a common parasite of Daphnia reveals the potential importance of free-living stages to epidemic dynamics, and suggests that it is important to consider environmental reservoirs when studying disease dynamics.
\end{abstract}

KEY WORDS: Spores - Daphnia dentifera - Daphnia pulicaria - Curse of the pharaoh $\cdot \mathrm{qPCR} \cdot$ Environmental transmission · Pathogen

\section{INTRODUCTION}

By definition, parasites are intimately associated with their hosts (Begon et al. 1996). Yet many parasites produce free-living infectious stages (e.g. Ebert 2005, Kuris et al. 2008, Saunders et al. 2008), some of which can persist in the environment for substantial lengths of time (e.g. Pepper \& Gentry 2002, Decaestecker et al. 2004). The following 2 questions arise: (1) What are parasites doing when they are not in their hosts? (2) What are the consequences of the dynamics of the free-living stage for infections in focal hosts?

Free-living stages of parasites have the potential to strongly influence the ecology and evolution of infectious diseases (Anderson \& May 1981, Holt \& Pickering 1985, Ewald 1994). For example, spatial variation in the density of free-living infectious stages could create gradients in the risk of infection. These gradients should affect spatial patterns of parasitism (Decaestecker et al. 2002). For diseases like cholera, an understanding of the ecology of free-living stages has enabled dramatic improvements to be made in management strategies (Colwell et al. 2003). From an evolutionary standpoint, the ability of parasites to produce free-living stages is predicted to be important for the evolution of virulence. Specifically, it has been suggested that the ability to produce long-lived infectious stages enables the evolution of very high virulence in parasites, a phenomenon known as the 'curse of the pharaoh' (Ewald 1993, 1994, Gandon 1998). Normally, parasites are thought to face constraints on virulence: if virulence is too high, the parasite might kill its host 
before it can be successfully transmitted to another host; if the parasite can produce long-lived infectious stages, it removes this constraint, allowing for high virulence (Ewald 1993).

Despite the clear ecological and evolutionary importance of free-living stages, for most diseases, very little is known about these stages. Historically, difficulties associated with tracking microbes in the environment probably contributed to this deficit. However, advances in molecular techniques now allow the tracking of microbial populations in nature (e.g. Church et al. 2005, Wetz et al. 2008, Thomas et al. 2009). In this study, we used quantitative PCR (qPCR) to study spatiotemporal variation of a common, virulent aquatic parasite, Spirobacillus cienkowskii, that infects the crustacean grazer Daphnia (Rodrigues et al. 2008). We were particularly interested in (1) the density of freeliving cells of $S$. cienkowskii, (2) whether there was significant spatial and/or temporal heterogeneity in the densities of these cells, (3) whether patterns of free-living cell density correlated with spatiotemporal patterns of infection, and (4) how long free-living stages could persist outside the host.

\section{MATERIALS AND METHODS}

Study system and field sampling. We studied the freshwater zooplankters Daphnia dentifera and Daphnia pulicaria (Crustacea: Cladocera) and their bacterial endoparasite Spirobacillus cienkowskii. Daphnia is an ecologically important freshwater invertebrate (Colbourne et al. 2005) and has emerged as a model system for studies of infectious diseases (Ebert 2005, 2008). $S$. cienkowskii is a member of the Deltaproteobacteria and is a widespread and highly virulent bacterial parasite of Daphnia (Duffy \& Hall 2008, Rodrigues et al. 2008, Duffy et al. 2010). Unfortunately, we have not been able to cultivate $S$. cienkowskii outside its host, despite trying a wide variety of conditions (including anaerobiosis, $4 \% \mathrm{O}_{2}$ and $21 \% \mathrm{O}_{2}$ ) and media (J. L. M. Rodrigues, S. H. Thomas, M. A. Duffy unpubl. data). The mechanism by which $S$. cienkowskii kills its host is also unknown. S. cienkowskii is distinguished by having a tightly coiled morphology (Rodrigues et al. 2008). Because it is very small (mean length: $3.5 \mu m_{i}$ mean width: $1.1 \mu m_{i}$ Rodrigues et al. 2008), it is likely to be easily ingested by daphniid hosts.

We focused on the Daphnia dentifera and D. pulicaria populations in Sportsman's Lake (Vermilion County, Illinois, USA). Sportsman's Lake is a stratified, eutrophic lake, $16 \mathrm{~m}$ deep, that is dominated by $D$. pulicaria and D. dentifera (Cáceres et al. 2005), both of which host Spirobacillus cienkowskii (Rodrigues et al. 2008, Duffy et al. 2010).
We quantified host density, the prevalence of infection, and the prevalence of the free-living parasite every week from June to October 2009. We used a Wisconsin-style bucket net (153 $\mu \mathrm{m}$ mesh) to collect 6 bottom-to-surface zooplankton samples on each sampling date; the net was towed through approximately 1961 of water on each tow. Samples were always collected from the deepest portion of the lake. On each sampling date, 3 of the samples were pooled and preserved in $95 \%$ ethanol for density estimates, and the other 3 were pooled and kept alive for quantification of infection. To determine the prevalence of infection in the live samples, we examined at least 400 Daphnia of each species and counted the number of $D$. dentifera and D. pulicaria that were infected with Spirobacillus cienkowskii; infections are readily apparent under a dissecting microscope owing to the vibrant scarlet coloration that results from infection (Metchnikoff 1889, Rodrigues et al. 2008). The prevalence of infection was determined as the number of infected hosts relative to the total number of hosts counted. In the case of $S$. cienkowskii infections that were present but below the detection limit (that is, when scarlet-colored individuals were observed in the overall sample, but not in the subsample that was scanned for infections), the 'percent infected' value was set at $0.125 \%$ (half of our sample resolution of $1 / 400=0.25 \%$ ). Our overall measure of infection is the sum of the prevalence of infection in the 2 host species. As in previous studies (Duffy et al. 2005, Duffy \& Hall 2008), we consider $>1 \%$ infection to be an epidemic.

To determine the implications of the observed densities of free-living Spirobacillus cienkowskii cells for encounter rates between S. cienkowskii and Daphnia, we combined estimates of feeding rates (based on Burns 1969, Sarnelle \& Wilson 2008) with information on temperature and on the density of $S$. cienkowskii. At $20^{\circ} \mathrm{C}$ (typical at $5 \mathrm{~m}$ depth in this lake; C. Bertram \& C. E. Cáceres unpubl. data), an individual Daphnia, $2 \mathrm{~mm}$ in length, can filter approximately $35 \mathrm{ml}$ in $24 \mathrm{~h}$ (Burns 1969). Modifying this clearance rate to account for the effects of temperature (based on Table 1 in Sarnelle \& Wilson 2008), a $2 \mathrm{~mm}$ long Daphnia can filter approximately $12 \mathrm{ml}$ in $24 \mathrm{~h}$ at $6^{\circ} \mathrm{C}$ (typical of temperatures at the sediment-water interface [SWI] in this lake; C. Bertram \& C. E. Cáceres unpubl. data). These volumes were combined with estimates of the density of the free-living stage of $S$. cienkowskii to determine the approximate number of free-living cells that a Daphnia would have encountered in different habitats.

In addition, the diel vertical distribution of Daphnia was assessed on 1 occasion, mid-epidemic (29 to 30 July 2009). We collected discrete water samples at $1 \mathrm{~m}$ increments to assess the vertical distribution of Daphnia at the deepest point in the lake, using a $12 \mathrm{l}$ 
Schindler-Patalas plankton sampler (Wildlife Supply Company); we collected 3 replicate samples at each depth. The day samples were collected between 11:00 and $12: 15 \mathrm{~h}$, and the night samples were collected between 22:45 and 00:15 h. Samples were first run through a screen (mesh size $153 \mu \mathrm{m}$ ) to remove excess water, then examined live on a glass microscope slide under a dissecting microscope at 25 to $50 \times$ magnification for the presence of uninfected and $S$. cienkowskiiinfected $D$. dentifera and $D$. pulicaria. These data were then used to compare the vertical distribution of infected Daphnia with the vertical distribution of freeliving S. cienkowskii (see next paragraph). Based on our results regarding the vertical distribution of freeliving cells, we were particularly interested in whether there was a vertical gradient in the prevalence of infection, with higher prevalence deep in the lake. We used Proc GLM in SAS 9.1 to analyze these data. Time (day vs. night) was treated as a class variable, while depth was treated as a continuous variable, because we were interested in trends associated with depth. Data on the prevalence of infection were arcsine square root-transformed prior to analysis (Sokal \& Rohlf 2001).

We also quantified the densities of free-living Spirobacillus cienkowskii every $14 \mathrm{~d}$, on average, between June and October 2009 using qPCR. Samples were collected at the same time and from the same area from which plankton tows were collected. We were interested in spatial variation in the density of $S$. cienkowskii, so we collected samples (in triplicate) from depths of 5 and $10 \mathrm{~m}$ (with a Van Dorn water sampler) and at the SWI (with a $6^{\prime \prime} \times 6^{\prime \prime} \times 6^{\prime \prime}$ Ekman-style dredge). Samples were put in sterile $50 \mathrm{ml}$ centrifuge tubes and kept on ice or refrigerated until analysis. While samples were collected with different devices, we always used the same volume of material for our analysis, and, therefore, the results should be comparable. To compare how the densities of free-living $S$. cienkowskii compared with densities of the bacterium in infected hosts, we collected infected individuals on 13 August 2009. Infected individuals $(n=3)$ were placed singly in $1 \mathrm{ml}$ of water, shipped overnight on ice from Illinois to Georgia, then crushed with a pestle for DNA extraction. While time-series data on the average densities of $S$. cienkowskii contained within infected hosts could yield interesting information (particularly on changes in the virulence of $S$. cienkowskii and/or the tolerance of Daphnia), such an analysis was beyond the scope of this study. Therefore, we have data only for a comparison of cell densities within hosts vs. densities in the environment from a single date.

Laboratory microcosms. We used laboratory microcosms to determine the longevity of free-living Spirobacillus cienkowskii cells. Water and flocculent sediments were collected from the SWI (using a Van Dorn water sampler, rather than the Ekman dredge used to collect the SWI samples for the time-series described above) and the sediment on 13 August 2009 and shipped overnight on ice from Illinois to Georgia. Samples were immediately transferred to 11 widemouth bottles that were either brown or darkened by covering with aluminum foil to prevent algal growth. The SWI samples were combined with sediment $(50 \mathrm{ml}$ sediment plus $500 \mathrm{ml}$ SWI). Ten microcosms were established; 5 replicates were incubated at $4^{\circ} \mathrm{C}$ (representative of the cold temperatures near the SWI) while the other 5 microcosms were incubated at $20^{\circ} \mathrm{C}$. Microcosms were incubated without shaking, held steady for sampling to keep water and sediment sampling separate, and then shaken before returning to the incubator to simulate periodic disruptions. We were unable to quantify $S$. cienkowskii in the sediment-only samples due to low qPCR sensitivity for the sediment samples; this was a problem for samples collected both with a Van Dorn water sampler and with the Ekman dredge.

Quantitative PCR. We determined the abundance of Spirobacillus cienkowskii in infected hosts, in the environment, and in the laboratory microcosms using qPCR. DNA from infected animals and microcosm sediments was extracted using the MO-BIO PowerSoil DNA Isolation kit. For the water and SWI samples, a $50 \mathrm{ml}$ quantity from each sample was vacuum filtered using a vacuum manifold equipped with a $200 \mathrm{ml}$ polysulfone filter funnel, $0.2 \mu \mathrm{m}$ Supor membrane disc filters (Pall Life Sciences) and a glass-fiber filter (Whatman GF/F). The Supor membrane filters were then extracted using the MO-BIO PowerWater DNA Isolation kit.

Specific primers targeting conserved regions of the 16S rRNA gene of Spirobacillus cienkowskii were designed for qPCR based on previously published primers (Rodrigues et al. 2008) and the nearly complete 16S rRNA gene sequence obtained from the NCBI database (accession number: EU220836). 16S rRNA gene sequences were aligned using MEGA4 (Tamura et al. 2007). The 16S rRNA gene alignment was examined visually, and primers were selected based on a region of the 16S rRNA gene specific to $S$. cienkowskii. BLAST analysis against the NCBI nonredundant database suggested primer specificity. The 0058F/462R primer pair (0058F: 5'-AAG TCG GAC GGA GGT AGC-3'; 462R: 5'-CAG ACT ATT AAC CTG CTT TCC CTT CTC-3') was based on primers described previously (Rodrigues et al. 2008) but redesigned to be used with SYBR Green detection chemistry (Invitrogen). The 462R primer was selected to be paired with the previously published (Rodrigues et al. 2008) S- ${ }^{*}$-Smet-0058-a-S-18 primer in order to achieve an appropriate amplicon size for qPCR. The expected size of the amplicon is $404 \mathrm{bp}$, a small size that pro- 
motes more efficient amplification 1 . Amplification was performed using the ABI 7500 Fast Real-Time PCR System. Default parameters for SYBR Green amplification with melting curve analysis were used according to software version 2.0.1. Each reaction included SYBR Green PCR Master Mix (1×), $500 \mathrm{nM}$ of each primer, and $2 \mu \mathrm{l}$ of template per $20 \mu \mathrm{l}$ reaction. Eight-point calibration curves containing known copy numbers of the S. cienkowskii 16S rRNA gene were prepared using pCR2.1 plasmid constructs generated using a TOPO TA cloning kit (Invitrogen). Melting curve analyses were used to reduce false positives associated with non-specific amplification ${ }^{1}$. Samples were considered below the detection limit when values fell below the point at which non-specific amplification was observed on melting temperature profiles and estimated at one half of the lowest standard in the linear calibration curve.
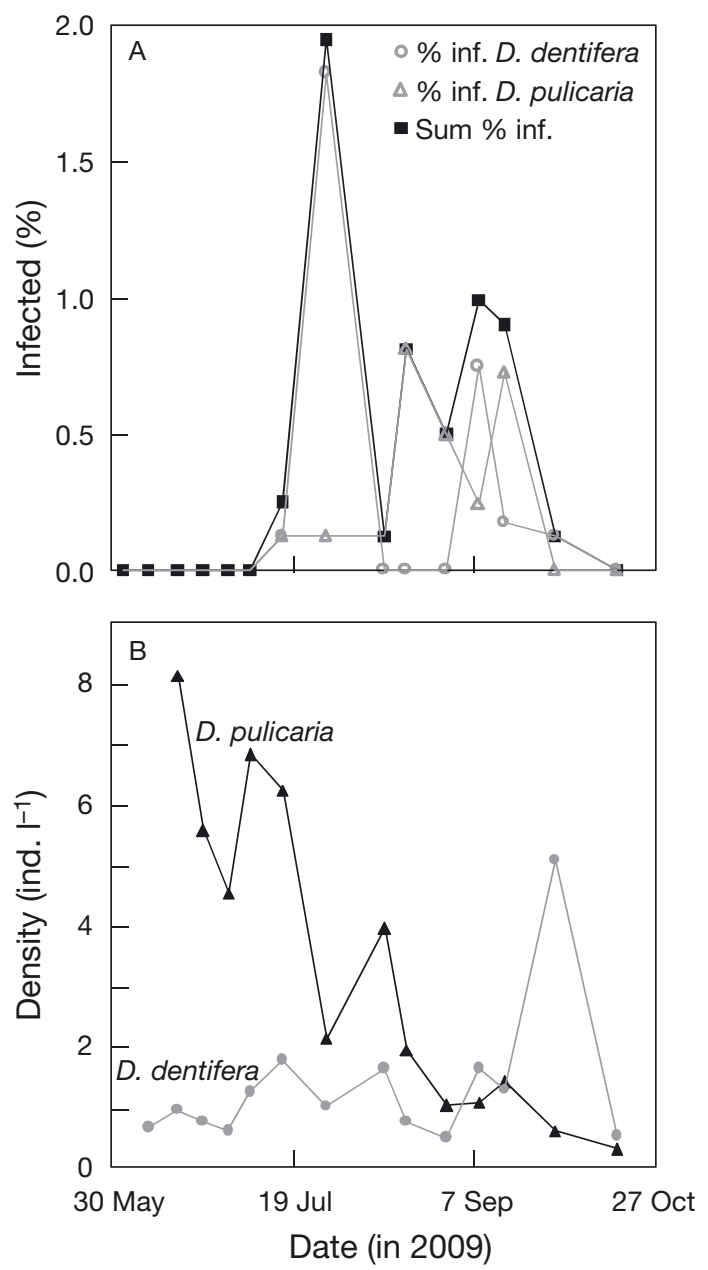

Fig. 1. Time-series of (A) Spirobacillus cienkowskii infections in Daphnia, and (B) density of D. dentifera and D. pulicaria in Sportsman's Lake, Illinois, USA. In (A), the squares represent the summed prevalence of infection in the 2 host species; \% inf.: percent infected
Plasmid standards amplified at concentrations between $3.5 \times 10^{1}$ and $3.5 \times 10^{8}$ copies per reaction. Spirobacillus cienkowskii was detectable at densities as low as $10^{2.0} \pm 10^{0.5}$ cells ml $^{-1}$ (averaged over $3 \mathrm{qPCR}$ standard curves). Unfortunately, sediment sample

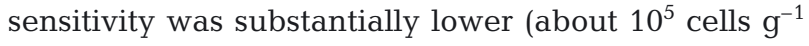
sediment) because the presence of inhibitors in the sediment necessitated a 1:10 dilution of the sample. Therefore, we were unable to obtain estimates of $S$. cienkowskii densities in sediment samples. After this study was completed, we discovered that sample resolution is much better when using a Macherey-Nagel (Bethlehem) NucleoSpin Soil kit to isolate DNA from sediments. Thus, in the future, we hope to greatly improve our detection limit. In addition, using fluorescent in situ hybridization (FISH), as was used in the Rodrigues et al. (2008) study, might allow for a much lower detection limit.

We looked for differences between the densities measured at the 3 different spatial locations $(5 \mathrm{~m}, 10 \mathrm{~m}$ and SWI) using analysis of variance (ANOVA) in Systat 12 ; location was modeled as a class variable. We also used Systat 12 to correlate data on Spirobacillus cienkowskii densities at $5 \mathrm{~m}, 10 \mathrm{~m}$ and at the SWI with the prevalence of infection in Daphnia on the next sampling date.

\section{RESULTS}

Daphnia pulicaria and D. dentifera were both infected with Spirobacillus cienkowskii in Sportsman's Lake (Fig. 1). S. cienkowskii infections first appeared in mid-July and were observed until late September. The epidemic was small, reaching a peak of $1.8 \%$ in $D$. dentifera and $0.8 \%$ in D. pulicaria.

As expected, infected Daphnia contained very high densities of Spirobacillus cienkowskii cells: $\sim 10^{8}$ cells per individual (mean log density \pm 1 SE: $8.005 \pm 0.25$ ). Densities of free-living $S$. cienkowskii cells were several orders of magnitude lower than those found within infected hosts (Fig. 2). However, there were still substantial numbers of $S$. cienkowskii cells outside the host, with densities as high as 653 cells ml $^{-1}$ at $5 \mathrm{~m}$, 925 cells ml $^{-1}$ at $10 \mathrm{~m}$, and 4275 cells ml$^{-1}$ at the SWI (Fig. 2). There were significant spatial differences in the densities of free-living $S$. cienkowskii $\left(F_{2,30}=5.6\right.$, $\mathrm{p}=0.008$ ), with densities highest at the SWI (Fig. 2).

By combining these observed densities of free-living Spirobacillus cienkowskii cells with estimates of feeding rates (see 'Materials and methods'), we can deter-

\footnotetext{
1ABI (2005) Applied Biosystems 7900HT Fast Real-Time PCR System and 7300/7500 Real-Time PCR Systems: Chemistry Guide 4348358 Rev. E
} 


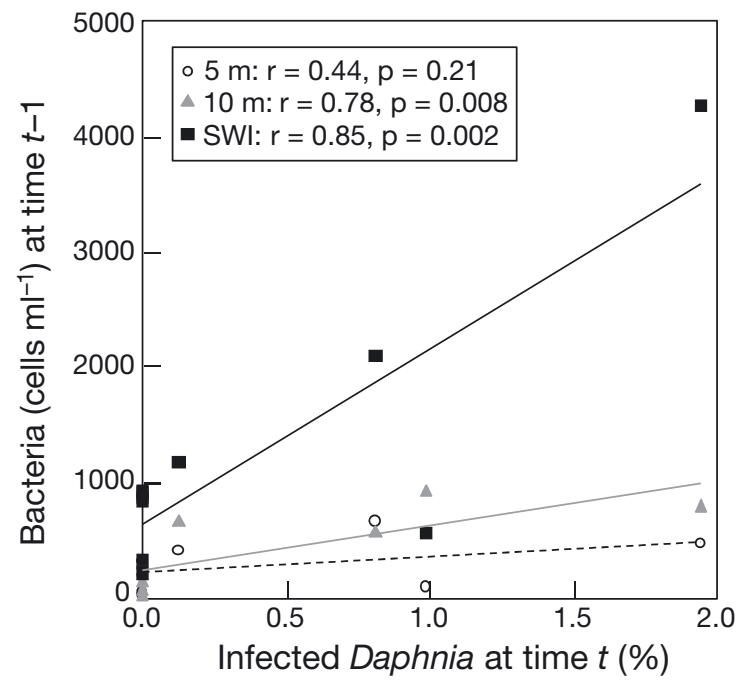

Fig. 2. Correlation between density of free-living stages of Spirobacillus cienkowskii and the percentage of $S$. cienkowskii-infected Daphnia at the next time point. Data are shown for samples from the water column (5 and $10 \mathrm{~m}$ depth) and the sediment-water interface (SWI)

mine the implications of these observed densities for encounter rates between Daphnia and free-living $S$. cienkowskii. During the highest densities of free-living $S$. cienkowskii that were observed at $5 \mathrm{~m}$ during this study (653 cells ml ${ }^{-1}$ ), a $2 \mathrm{~mm}$-long Daphnia residing at $5 \mathrm{~m}$ would have encountered $\sim 23000 \mathrm{~S}$. cienkowskii cells $\mathrm{d}^{-1}$; at the lowest densities observed at $5 \mathrm{~m}$ during this study (14.4 cells ml $\left.{ }^{-1}\right)$, that individual would have encountered $\sim 500$ cells d$^{-1}$. If that $2 \mathrm{~mm}$-long Daphnia were residing at the SWI during the period of highest densities of free-living S. cienkowskii (4275 cells ml-1 ${ }^{-1}$, it would have encountered $\sim 51000 \mathrm{~S}$. cienkowskii cells $\mathrm{d}^{-1}$; at the lowest densities observed at the SWI $\left(204 \mathrm{cells} \mathrm{ml}^{-1}\right.$ ), that individual would have encountered $\sim 2400$ cells d $^{-1}$.

Because of the significant spatial variation in the density of free-living cells, we asked whether there were also spatial patterns in the prevalence of infection in Daphnia. We found a significant relationship between depth and the prevalence of infection (depth: $F_{1,93}=6.77$, $\mathrm{p}=0.01$ ) (Fig. 3). However, contrary to what we expected based on free-living cells, there tended to be a higher prevalence of infection at shallower depths - particularly high at a depth of $\sim 5$ to $8 \mathrm{~m}$ (Fig. 3). There was no significant effect of time (that is, day vs. night), and the time $\times$ depth interaction was also not significant (time: $F_{1,93}=0.04, \mathrm{p}=0.85$, time $\times$ depth: $F_{1,93}=1.57, \mathrm{p}=0.21$ ).

In addition to showing spatial variation, densities of Spirobacillus cienkowskii showed temporal variation (Fig. 2). High densities of free-living S. cienkowski cells preceded maximum infection levels in Daphnia. There was a positive correlation between the density

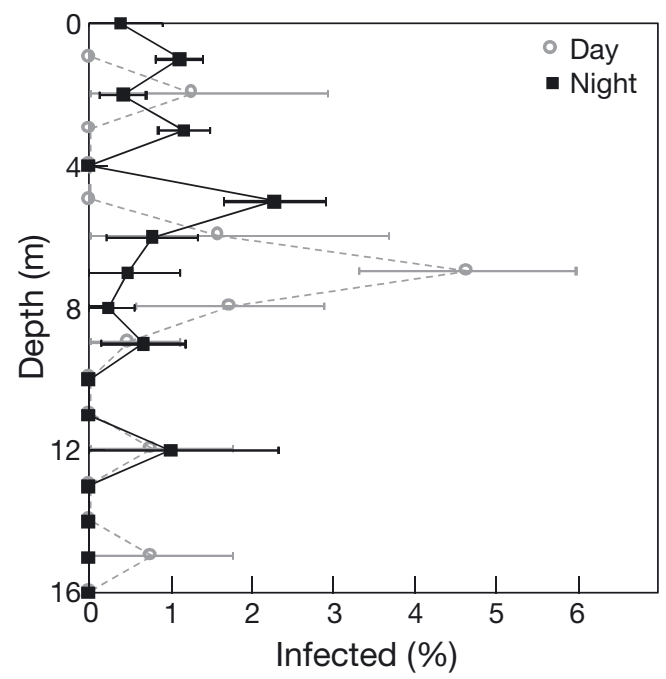

Fig. 3. Daphnia pulicaria and D. dentifera. Diel vertical distribution of Spirobacillus cienkowskii-infected D. pulicaria and $D$. dentifera. Means $( \pm 1 \mathrm{SE})$ are shown. There was no significant difference between day and night distribution $\left(F_{1,93}=\right.$ $0.04, \mathrm{p}=0.85$ ), but there was a significant vertical trend in the prevalence of $S$. cienkowskii infection $\left(F_{1,93}=6.77, \mathrm{p}=0.01\right)$, with higher prevalence at shallower depths

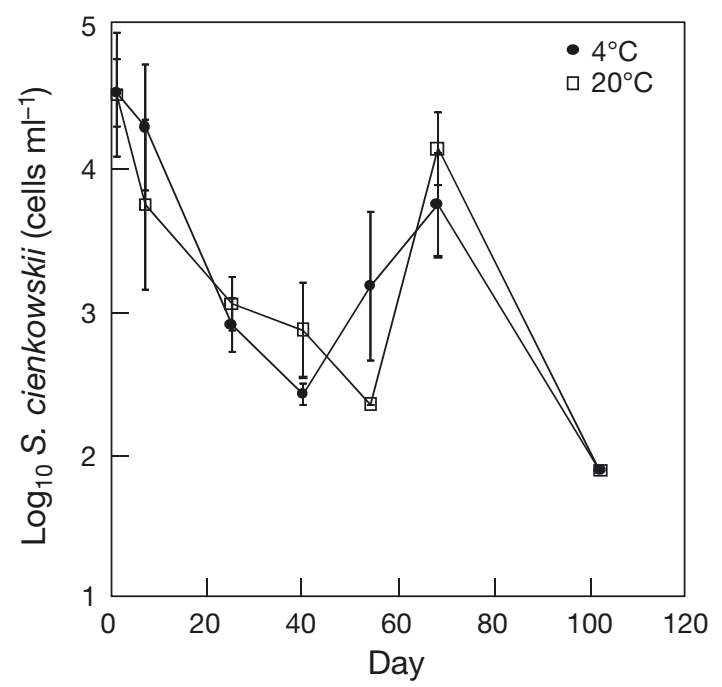

Fig. 4. Spirobacillus cienkowskii. Change in the density of the bacterium at the sediment-water interface (SWI) in microcosms incubated at 4 and $20^{\circ} \mathrm{C}$ in the laboratory. Means $( \pm 1 \mathrm{SE})$ are shown. On the last day of the experiment (day 102), all microcosms were below the detection limit; therefore, the detection limit for this day is plotted

of free-living stages in environmental reservoirs and the prevalence of infection in Daphnia on the subsequent sampling date (Fig. 2). However, this pattern was statistically significant only for the $10 \mathrm{~m}$ and SWI samples (Fig. 2).

In our experiment, designed to determine whether the parasite could survive outside the host, we found 
that cells were detectable under simulated environmental conditions for at least $70 \mathrm{~d}$ (Fig. 4). Interestingly, in the sample collected on Day 68, there appeared to be an increase in the cell density of Spirobacillus cienkowskii at both temperatures (Fig. 4).

\section{DISCUSSION}

Many parasites produce free-living infectious stages. Despite the ecological and evolutionary importance of these stages, very little is known about their spatiotemporal distribution or about the relationships between the dynamics of free-living stages and infection dynamics in focal hosts. We demonstrated that (1) there were substantial numbers of free-living cells of a common bacterial pathogen, Spirobacillus cienkowskii, (2) there was significant spatial heterogeneity in the densities of these cells, with the highest densities at the SWI, (3) temporal changes in densities of free-living stages were followed by changes in the prevalence of infection in the hosts, D. pulicaria and $D$. dentifera, and (4) free-living stages of S. cienkowskii persisted for months outside the host.

We found spatial patchiness of Spirobacillus cienkowskii free-living stages, with densities highest at the SWI. It is unlikely that the observed spatial patterns were driven by settling of spores; $S$. cienkowskii cells are small $(\sim 1 \times 3.5 \mu \mathrm{m}$; Rodrigues et al. 2008), so settling is likely to be negligible (Lee 2008). However, densities might be higher at the SWI due to settling of corpses of infected Daphnia, which would then decompose at the SWI.

Regardless of the cause, the observed spatial patchiness in the density of Spirobacillus cienkowskii was expected to have effects on patterns of infection. A previous study suggested that high densities of parasite spores near the sediment led to a gradient in the risk of parasitism that was associated with habitat use (Decaestecker et al. 2002). Specifically, Daphnia residing deeper in the water column should be exposed to higher densities of parasites (Decaestecker et al. 2002). Populations of both $D$. dentifera and $D$. pulicaria show variation in migration behavior (Leibold \& Tessier 1997, Duffy 2010), with some morphs spending more time in deeper waters. Based on our results, we might expect these morphs to experience greater exposure to parasites, which might then lead to spatial patchiness in infections - specifically, one might expect a higher prevalence of infection deeper in the water column. However, in our study, there tended to be a higher prevalence of infection at shallower depths (especially at $\sim 5$ to $8 \mathrm{~m}$ ), rather than near the SWI. Our findings are supported by an earlier study that also did not find evidence of vertical gradients in S. cienkowskii infec- tions (Hall et al. 2005). Therefore, even though densities of free-living $S$. cienkowskii cells are highest at the SWI, this does not appear to lead to a higher prevalence of infection at greater depth. At present, we do not know what drives this pattern. One possible explanation is the low temperature at the SWI (6 to $8^{\circ} \mathrm{C}$ ). In work on a different parasite of Daphnia, Metschnikowia bicuspidata, we have found a sharp decline in parasite infectivity at temperatures below $15^{\circ} \mathrm{C}$ (Hall et al. 2006).

In addition to spatial variation, there were temporal changes in the density of free-living infectious stages of Spirobacillus cienkowskii. The correlation between density of free-living stages and infections in Daphnia was of particular interest: increases in free-living densities were correlated with an increased prevalence of infection on the subsequent sampling date, suggesting that increases in free-living stages might trigger epidemics. While the exact mode of transmission of S. cienkowskii is unclear, Daphnia presumably acquire infectious particles from the environment, perhaps while feeding (Hall et al. 2007). We also found, for D. pulicaria, a significant negative correlation between the prevalence of infection and host density on the subsequent sampling date $(\mathrm{r}=-0.62, \mathrm{p}=0.03)$. Previously, we found strong effects of S. cienkowskii epidemics on Daphnia population dynamics (Duffy \& Hall 2008). However, it is also possible that the observed decline in $D$. pulicaria may be driven by its natural seasonal phenology (e.g. Hu \& Tessier 1995), as opposed to the parasite.

What causes increases in the densities of free-living Spirobacillus cienkowskii? While sediments are known to serve as reservoirs of infectious stages of the parasites of Daphnia (Decaestecker et al. 2004), resuspension of spores from the sediments seems unlikely in this case because the lakes were stratified at the time of the increase (in June to July; C. Bertram \& C. E. Cáceres unpubl. data). However, a similar increase in densities of free-living cells was seen in our microcosm experiment. Together, these data suggest that $S$. cienkowskii may be able to grow outside its host.

Free-living infectious stages of Spirobacillus cienkowskii were able to persist in laboratory microcosms for over 2 mo before declining to below our method's detection limit after approximately 3 mo. The ability of a parasite to produce long-lived infectious stages has been predicted to enable high virulence (Ewald 1993, 1994, Gandon 1998). S. cienkowskii is highly virulent-once infection becomes apparent, hosts generally die within 1 to 4 d (Duffy \& Hall 2008) — and it is possible that this high virulence arises, at least in part, from the ability of free-living infective stages to persist in the environment. However, epidemics of $S$. cienkowskii generally occur only 1 or 2 times per year (Duffy et al. 2005, Duffy \& Hall 2008, M. A. Duffy \& C. 
E. Cáceres unpubl. data), yet our study indicated that $S$. cienkowskii could survive for only 2 to 3 mo outside the host. Therefore, it is unclear how $S$. cienkowskii persists in the environment between epidemics. One possibility is that $S$. cienkowskii cells persist longer in lakes than in our laboratory microcosms, perhaps due to differences in environmental conditions (such as oxygen levels). Another possibility is that the ability of $S$. cienkowskii to be incorporated into the diapausing egg cases ('ephippia') of Daphnia is important to its ability to persist in the environment while its host is dormant. Indeed, we have seen visual evidence of $S$. cienkowskii within Daphnia ephippia (Rodrigues et al. 2008), and have also successfully amplified S. cienkowskii DNA from Daphnia ephippia (M. A. Duffy, K. van Rensburg, S. H. Thomas unpubl. data). However, further study is required to determine what proportion of ephippia contain S. cienkowskii, and what densities of $S$. cienkowskii are contained within ephippia.

Our study suggests that qPCR approaches can help to uncover the role of free-living stages in the dynamics of parasitism in natural populations. It was relatively easy to design specific primers to track dynamics for this system because Spirobacillus cienkowskii is a deeply branching member of the Deltaproteobacteria (Rodrigues et al. 2008). However, similar approaches have been used to track the distribution of non-pathogenic bacteria in environmental samples, and to distinguish between very closely related strains (Thomas et al. 2009). We suggest that these techniques should be applied more broadly to study free-living stages of parasites, and that doing so will yield important insights into the role of these stages in the ecological and evolutionary dynamics of pathogens.

Acknowledgements. We thank F. Loeffler and J. Hatt for use of the qPCR machine, and 2 anonymous reviewers for their comments. This work was supported by the Georgia Institute of Technology and by the National Science Foundation (DEB0827396 to M.A.D. and DEB-0614316 to C.E.C.).

\section{LITERATURE CITED}

Anderson RM, May RM (1981) The population dynamics of microparasites and their invertebrate hosts. Philos Trans R Soc Lond Ser B Biol Sci 291:451-524

Begon M, Harper JL, Townsend CR (1996) Ecology: individuals, populations and communities, 3rd edn. Blackwell Science, Oxford

Burns CW (1969) Relation between filtering rate, temperature, and body size in four species of Daphnia. Limnol Oceanogr 14:693-700

Cáceres CE, Mulvany SL, Paczolt KA, Steiner CF (2005) Cladoceran community assembly in a recently created lake. Int Ver Theor Angew Limnol Verh 29:1020-1024

> Church MJ, Jenkins BD, Karl DM, Zehr JP (2005) Vertical distributions of nitrogen-fixing phylotypes at Stn ALOHA in the oligotrophic North Pacific Ocean. Aquat Microb Ecol 38:3-14

Colbourne JK, Singan VR, Gilbert DG (2005) wFleaBase: The Daphnia genome database. BMC Bioinformatics 6:45

Colwell RR, Huq A, Islam MS, Aziz KMA and others (2003) Reduction of cholera in Bangladeshi villages by simple filtration. Proc Natl Acad Sci USA 100:1051-1055

Decaestecker E, De Meester L, Ebert D (2002) In deep trouble: habitat selection constrained by multiple enemies in zooplankton. Proc Natl Acad Sci USA 99:5481-5485

> Decaestecker E, Lefever C, De Meester L (2004) Haunted by the past: evidence for dormant stage banks of microparasites and epibionts of Daphnia. Limnol Oceanogr 49: 1355-1364

Duffy MA (2010) Ecological consequences of intraspecific variation in lake Daphnia. Freshw Biol 55:995-1004

Duffy MA, Hall SR (2008) Selective predation and rapid evolution can jointly dampen effects of virulent parasites on Daphnia populations. Am Nat 171:499-510

Duffy MA, Hall SR, Tessier AJ, Huebner M (2005) Selective predators and their parasitized prey: Are epidemics in zooplankton under top-down control? Limnol Oceanogr 50:412-420

Duffy MA, Cáceres CE, Hall SR, Tessier AJ, Ives AR (2010) Temporal, spatial and between-host comparisons of patterns of parasitism in lake zooplankton. Ecology 91: 3322-3331

Ebert D (2005) Ecology, epidemiology and evolution of parasitism in Daphnia. National Library of Medicine (US), National Center for Biotechnology Information, Bethesda, MD

Ebert D (2008) Host-parasite coevolution: insights from the Daphnia-parasite model system. Curr Opin Microbiol 11: 290-301

Ewald PW (1993) The evolution of virulence. Sci Am 268: 86-93

Ewald PW (1994) Evolution of infectious disease. Oxford University Press, Oxford

- Gandon S (1998) The curse of the pharaoh hypothesis. Proc Biol Sci 265:1545-1552

> Hall SR, Duffy MA, Tessier AJ, Cáceres CE (2005) Spatial heterogeneity of daphniid parasitism in lakes. Oecologia 143:635-644

Hall SR, Tessier AJ, Duffy MA, Huebner M, Cáceres CE (2006) Warmer does not have to mean sicker: temperature and predators can jointly drive timing of epidemics. Ecology 87:1684-1695

> Hall SR, Sivars-Becker L, Becker C, Duffy MA, Tessier AJ, Cáceres CE (2007) Eating yourself sick: transmission of disease as a function of feeding biology of hosts. Ecol Lett 10:207-218

> Holt RD, Pickering J (1985) Infectious disease and species coexistence: a model of Lotka-Volterra form. Am Nat 126:196-211

$>\mathrm{Hu}$ SS, Tessier AJ (1995) Seasonal succession and the strength of intra- and interspecific competition in a Daphnia assemblage. Ecology 76:2278-2294

Kuris AM, Hechinger RF, Shaw JC, Whitney KL and others (2008) Ecosystem energetic implications of parasite and free-living biomass in three estuaries. Nature 454: $515-518$

Lee RE (2008) Phycology, 4th edn. Cambridge University Press, Cambridge

Leibold MA, Tessier AJ (1997) Habitat partitioning by zooplankton and the structure of lake ecosystems. In: Streit B, Städler T, Lively CM (eds) Evolutionary ecology of freshwater animals. Birkhäuser Verlag, Basel, p 3-30 
Metchnikoff E (1889) Contributions à l'etude du pléomorphisme des bactériens. Ann Inst Pasteur (Paris) 3:165-170

Pepper IL, Gentry TJ (2002) Incidence of Bacillus anthracis in soil. Soil Sci 167:627-635

Rodrigues JLM, Duffy MA, Tessier AJ, Ebert D, Mouton L, Schmidt TM (2008) Phylogenetic characterization and prevalence of Spirobacillus cienkowskii: a red-pigmented, spiral-shaped bacterial pathogen of freshwater Daphnia species. Appl Environ Microbiol 74:1575-1582

Sarnelle O, Wilson AE (2008) Type III functional response in Daphnia. Ecology 89:1723-1732

Saunders SE, Bartelt-Hunt SL, Bartz JC (2008) Prions in the environment: occurrence, fate and mitigation. Prion 2:162-169

Editorial responsibility: Urania Christaki,

Wimereux, France
Sokal RR, Rohlf FJ (2001) Biometry, 3rd edn. WH Freeman, New York, NY

Tamura K, Dudley J, Nei M, Kumar S (2007) MEGA4: Molecular evolutionary genetics analysis (MEGA) software version 4.0. Mol Biol Evol 24:1596-1599

Thomas SH, Padilla-Crespo E, Jardine PM, Sanford RA, Löffler FE (2009) Diversity and distribution of Anaeromyxobacter strains in a uranium-contaminated subsurface environment with a nonuniform groundwater flow. Appl Environ Microbiol 75:3679-3687

> Wetz JJ, Blackwood AD, Fries JS, Williams ZF, Noble RT (2008) Trends in total Vibrio spp. and Vibrio vulnificus concentrations in the eutrophic Neuse River Estuary, North Carolina, during storm events. Aquat Microb Ecol 53:141-149

Submitted: December 1, 2010; Accepted: February 2, 2011 Proofs received from author(s): May 6, 2011 